\title{
Localizing Epileptic Focus with Interictal Scalp EEG in Patients with Focal Cortical Dysplasia
}

\author{
Ozgur Bilgin Topcuoglu' (D), Ipek Midi \\ ${ }^{1}$ Sureyyapasa Chest Diseases and Thorax Surgery Training and Research Hospital, Neurology Clinics, Istanbul, Turkey. \\ ${ }^{2}$ Marmara University, Faculty of Medicine, Department of Neurology, Istanbul, Turkey. \\ Correspondence Author: Ozgur Bilgin Topcuoglu \\ E-mail: ozgurbilgin1@yahoo.com \\ Received: $01.08 .2019 \quad$ Accepted: 23.08 .2019
}

\begin{abstract}
Objective: To assess the localizing value of interictal scalp EEG in epileptic focal cortical dysplasia (FCD) patients.

Methods: A retrospective observational study of EEG records of epileptic patients seen at the Marmara University Hospital was performed. EEG and MRI findings were evaluated to detect a possible correlation.

Results: EEG findings were consistent with MRI findings in 6 patients (37.5\%).

Conclusion: EEG findings were irrelevant in $62.5 \%$ ( $n: 10)$ of patients. Additional imaging techniques such as ictal SPECT, MEG etc. will clearly augment the success of lesion localisation in FCD patients.
\end{abstract}

Keywords: EEG, interictal, focal cortical dysplasia.

\section{INTRODUCTION}

Focal cortical dysplasia (FCD) is a common malformation of cerebral cortical development. FCD describes a wide range of abnormalities resulting from disruption in the migration of the maturing neurons, disturbance of programmed cell death in fetal brain and environmental factors (1). Association of FCD with epilepsy was first described by Taylor in 1971 (2) Five to $10 \%$ of all epilepsy patients have FCD (3). Intractable epilepsy remains the most common clinical presentation for all types of FCD (4). Seizures usually tend to start in early childhood, but may start at any age (5). In pediatric patients with drug-resistant epilepsy, up to $50 \%$ of patients have magnetic resonance imaging (MRI) visible FCD (3) Scalp electroencephalography (EEG) is one of the important tools to localize the epileptogenic zone (6). However, there are conflicting results from studies which evaluated the role of EEG in FCD $(7,8)$.

In this study we aimed to analyze the interictal scalp EEGs of a refined group of FCD patients to see if interictal scalp EEG correctly localized the epileptogenic zone.

\section{METHODS}

A retrospective observational study of EEG records of epileptic patients seen at the Marmara University Hospital, Turkey between January 2012 to December 2018 was performed. Patients who were diagnosed as FCD were included. Age, sex, EEG findings and MRI findings of the patients were retrieved. All EEGs are 30 minutes interictal scalp EEGs which were performed using the 10-20 system. Patients were grouped according to their demographic variables. EEG and MRI findings were evaluated to detect a possible correlation.

This is a retrospective descripitive study thus there was no control group. Since the patient group was relatively small, the results were not statistically analyzed and given as ratios and percentages.

\section{RESULTS}

Sixteen epileptic patients who were diagnosed as FCD were included in the study. Nine patients $(56.25 \%)$ were female while 7 patients $(43.75 \%)$ were male. Mean patient age was 35,375 years with ranging from 18 to 72 years old. 
Six patients(37.5\%) had FCD on left hemisphere, 5 patients $(31.25 \%)$ had on right hemisphere and 5 patients $(31.25 \%)$ had bilateral lesions.

$43.75 \%(n=7)$ of patients' lesions were found in frontal, 25 $\%(n=4)$ in perisilvie, $18.75 \%(n=3)$ in temporal, $6.25 \%(n=1)$ in parietal lobe. One patient $(6.25 \%)$ had bilateral dual pathology (mesial temporal sclerosis with occipital FCD).

EEG findings were normal in 7 patients (43.75\%) and pathological in 8 patients (56.25\%). EEG findings were consistent with MRI findings in 6 patients (37.5\%) and irrelevant in $62.5 \%(n=10)$ as shown at Table 1.

Table 1. MRI and EEG findings of the patients.

\begin{tabular}{|c|c|c|c|c|}
\hline $\begin{array}{c}\text { Patient } \\
\text { no }\end{array}$ & Sex & Age(years) & MRI findings & EEG findings \\
\hline $\mathbf{1}$ & 1 & 22 & Temporal(L) & Temporooccipital E.A.(L) \\
\hline $\mathbf{2}$ & 1 & 27 & Frontal (L) & Normal \\
\hline $\mathbf{3}$ & 1 & 56 & $\begin{array}{c}\text { MTS+occipital } \\
\text { (B) }\end{array}$ & Temporal E.A.(B) \\
\hline $\mathbf{4}$ & 0 & 35 & Frontal (R) & Normal \\
\hline $\mathbf{5}$ & 0 & 44 & Perisilvien (B) & Normal \\
\hline $\mathbf{6}$ & 1 & 34 & Temporal (R) & $\begin{array}{c}\text { Anterior temporal } \\
\text { E.A.(R) }\end{array}$ \\
\hline $\mathbf{7}$ & 0 & 35 & Perisilvien (B) & FIRDA \\
\hline $\mathbf{8}$ & 1 & 19 & Frontal (L) & $\begin{array}{c}\text { Bifrontal intermittant } \\
\text { slowing }\end{array}$ \\
\hline $\mathbf{9}$ & 0 & 18 & Temporal (L) & Normal \\
\hline $\mathbf{1 0}$ & 0 & 26 & Frontal (L) & Normal \\
\hline $\mathbf{1 1}$ & 1 & 46 & $\begin{array}{c}\text { Superior frontal } \\
(\mathrm{R})\end{array}$ & Normal \\
\hline $\mathbf{1 2}$ & 1 & 72 & Frontal (L) & Normal \\
\hline $\mathbf{1 3}$ & 0 & 25 & Parietal (R) & Frontocentral E.A.(R) \\
\hline $\mathbf{1 4}$ & 0 & 35 & Frontal(R) & Frontocentral E.A.(R) \\
\hline $\mathbf{1 5}$ & 1 & 43 & Perisilvien (B) & Jeneralized E.A. \\
\hline $\mathbf{1 6}$ & 1 & 29 & Perisilvien(R) & Frontal E.A. (R) \\
\hline
\end{tabular}

$0=$ male, $1=$ female,$L=$ left, $R=$ right, $B=$ bilateral, E.A=epileptifrom activity, FIRDA=Frontal intermittant rythmic delta activity

\section{DISCUSSION}

In this study we aimed to evaluate the localizing value of interictal scalp EEG in FCD. We found out that in $37.5 \%$ $(n=6)$ of our patients, EEG findings were consistent with MRI lesions.

Epilepsy, the most common manifestation of FCD can ocur at any age but most commonly develops in childhood (9). Seizures from FCD are commonly refractory to medical treatment (10). With the evolving modern imaging technologies such as MRI, 18-fluorodeoxyglucosepositron -emission tomography (FDG-PET), ictal-single photon emission computed tomography (SPECT) and magnetoencephalography (MEG), cortical dysplasia are more frequently diagnosed in epileptic patients (11). Certainly the MRI lesion is not enough for epilepsy surgery decision. It is necessary to meticulously determine where exactly the seizure arises. Despite the variation between different types of FCD, rythmic epileptiform discharges on interictal scalp EEG have been determined to correlate with the anatomic extent of the lesion $(7,8)$

Interictal and ictal scalp EEG findings have been formerly studied to demonstrate electrographic signs by Noachtar et al. (12) Lerner et al. has shown that interictal and ictal scalp EEG correlated with the region of cortical dysplasia in $49-68 \%$ of patients (13). Our findings are close but less supportive than the former studies. We showed that interictal scalp EEG only localized $37.5 \%$ of the FCD patients. There may be a few reasons for this discordance. One of them is clearly the relatively small number of patients. The second reason may be the lack of ictal scalp EEG implementation.

\section{CONCLUSION}

As a conclusion, our relatively different results from the previous studies may be interpretad as the necessity of dual practice of ictal and interictal scalp EEG in FCD patients. Additional imaging techniques such as ictal SPECT and MEG etc. should be performed to augment the success of lesion localisation clearly in FCD patients.

Acknowledgement: Special thanks to Mrs. Berrak Kızılap for her generous support in the EEG laboratory.

\section{REFERENCES}

[1] Sullivan LR, Kull LL, Sweeney DB, Davis CP. Cortical dysplasia: zones of epileptogenesis. Am J Electroneurodiagnostic Technol 2005; 45: 49-60.

[2] Taylor DC, Falconer MA, Bruton CJ, Corsellis JA. Focal dysplasia of the cerebral cortex in epilepsy. J Neurol Neurosurg Psychiatry 1971; 34: 369-387.

[3] Leach JL, Greiner HM, Miles L, Mangano FT. Imaging spectrum of cortical dysplasia in children. Semin Roentgenol 2014;49: 99-111.

[4] Tassi L, Colombo N, Garbelli R, Francione S, Lo Russo G, Mai R, Cardinale F, Cossu M, Ferrario A, Galli C, Bramerio M, Citterio A, Spreafico R. Focal cortical dysplasia: neurpathological subtypes, EEG, neuroimaging and surgical outcome. Brain 2002; 125: 1719-1732.

[5] Crino PB. Focal Cortical Dysplasia. Semin Neurol 2015: 35: 201208.

[6] Rosenow F, Luders H. Presurgical evaluation of epilepsy. Brain 2001; 124: 1683-1700.

[7] Krsek P, Pieper T, Karlmeier A, Hildebrandt M, Kolodziejczyk D, Winkler P, Pauli E, Blümcke I, Holthausen H. Different presurgical characteristics and seizure outcomes in children with focal cortical dysplasia type I or II. Epilepsia 2009; 50:125-137.

[8] Gambardella A, Palmini A, Andermann F, Dubeau F, Da Costa JC, Quesney LF, Andermann E, Olivier A. Usefulness of focal rythmic discharges on scalp EEG of patients with focal cortical dysplasia and intractable epilepsy. Electroencephalogr Clin Neurophysiol 1996; 98: 243-249.

[9] Gaitanis JN, Donahue J. Focal cortical dysplasia. Pediatric Neurology 2013; 49: 79-87. 
[10] Wyllie E, Comair YG, Kotagal P, Bulacio J, Bingaman W, Ruggieri P. Seizure outcome after epilepsy surgery in children and adolescents. Ann Neurol 1998; 44: 740-748.

[11] Hauptman JS, Mathern GW. Surgical treatment of epilepsy associated with cortical dysplasia: 2012 update. Epilepsia 2012;53:98-104.

[12] Noachtar S, Bilgin O, Rémi J, Chang N, Midi I, Vollmar C, Feddersen B. Interictal regional polyspikes in noninvasive
EEG suggest cortical dysplasia as etiology of focal epilepsies. Epilepsia 2009; 50: 550-555.

[13] Lerner JT, Salamon N, Hauptman JS, Velasco TR, Hemb M, Wu JY, Sankar R, Donald Shields W, Engel J Jr, Fried I, Cepeda $C$, Andre VM, Levine MS, Miyata $H$, Yong $\mathrm{WH}$, Vinters $\mathrm{HV}$, Mathern GW. Assessment and surgical outcomes for mild type I and severe type II cortical dysplasia: a critical review and the UCLA experience. Epilepsia 2009 ;50: 1310-1335. 